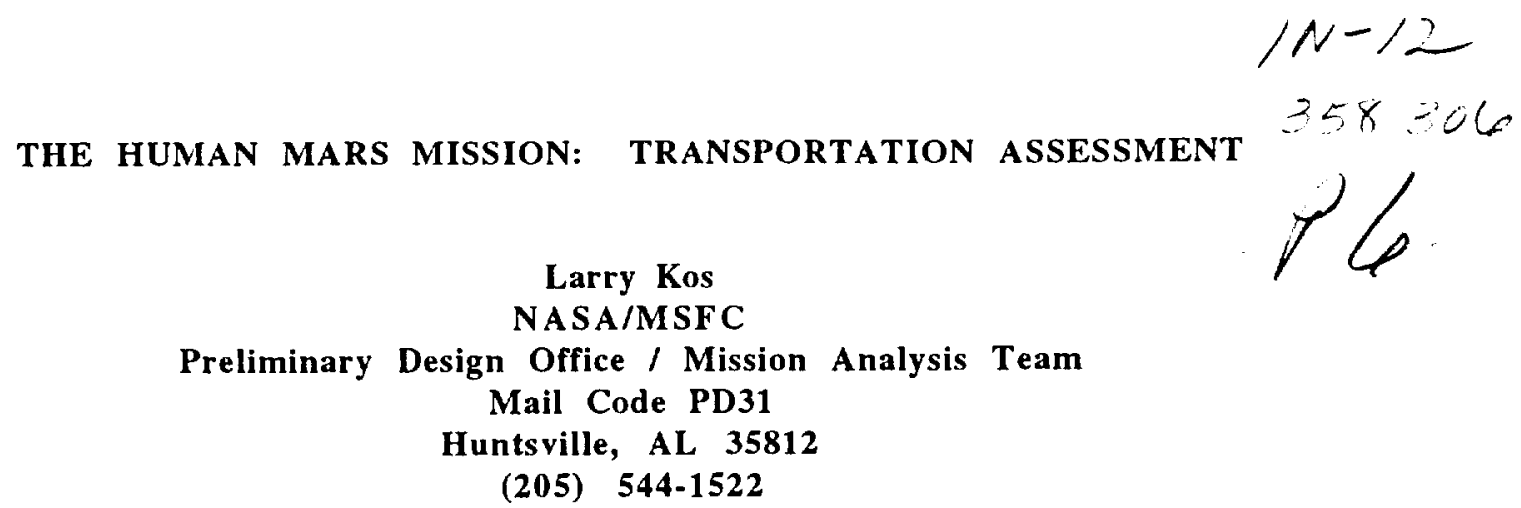

Ahstract

If funding is available, and for NASA planning purposes, the Human Mars Mission (HMM) is baselined to take place during the 2011 and 2013/2014 Mars opportunities. Two cargo flights will leave for Mars during the first opportunity, one to Mars orbit and the second to the surface, in preparation for the crew during the following opportunity. Each trans-Mars injection (TMI) stack will consist of a cargo / payload portion (currently coming in at between 65 and $78 \mathrm{mt}$ ) and a nuclear thermal propulsion (NTP) stage (currently coming in at between 69 and $77 \mathrm{mt}$ loaded with propellant) for performing the departure $\Delta V s$ to get on to the appropriate Mars trajectories. Three 66,700 $N$ thrust NTP engines comprise the TMI stage for each stack and perform a $\Delta V$ ranging from 3580 to $3890 \mathrm{~m} / \mathrm{s}$ as required by the trajectory (with gravity losses and various performance margins added to this for the total TMI $\Delta \mathrm{V}$ performed). This paper will discuss the current application of this NTP stage to a Human Mars mission, and project what implications a nuclear trans-Earth injection (TEI) stage as well as a bi-modal NTP stage could mean to a human visit to Mars.

\title{
INTRODUCTION
}

The Design Reference Mission (DRM) is the term used to describe the current Mars baseline architecture by the Exploration Transportation Office at MSFC, the Exploration Office at JSC, and the exploration community at large to compare and evaluate approaches to mission, system, and transportation concepts that could be used for human missions to Mars. It does not represent a final or recommended approach to human Mars missions. The DRM captures what is to be considered to be the "best" approach to human Mars missions, based on current understanding, and is continually in a process of improvement on the HMM concepts. An example of this, is the comparison of the description of this current mission proposal to that of previous major studies (Cohen 1989 and Stafford 1991). Note that this current "semi-direct" DRM has been built upon earlier versions of this architecture (Weaver 1993 and Weaver 1993).

\section{TRANSPORTATION OB.JECTIVES}

The objectives of the transportation system are to:

- Safely deliver to Mars and return to Earth of the HMM crew.

- Reliably deliver all cargo to Mars orbit and to Mars surface.

- Minimize development and recurring costs associated with transportation.

- Provide for an extendible type of transportation scheme for growth capability to enable later missions.

- Capture as many opportunities as possible of the 2009 15-year cycle with single TMI and TEI stage designs.

\section{TRANSPORTATION ASSUMPTIONS}

- Minimize both the mass and the cost of the transportation elements to the extent possible

- Limit the length of time that the crew is continuously exposed to the interplanetary space environment

- Nuclear Thermal Propulsion Specific Impulse $\left(\mathrm{I}_{3 \mathrm{p}}\right)$ : 960 seconds (-3\% for reactor cool-down losses)

- Chemical Propulsion Isp: 379 seconds 


\section{MISSION DESCRIPTION}

The mission design for the crew utilizes relatively fast transits (115 to 180 days) to and from Mars with long surface stays ( 18 to 22 months; 570 days nominal). Cargo missions are sent to Mars on an optimum low energy, long-transit-time trajectory. Figure I illustrates a top level mission sequence. All cargo is delivered to low Earth orbit (LEO) on an 80 metric tonne (mt) class Magnum-type launch vehicle (MLV). The DRM requires just one automatic rendezvous and capture (AR\&C) operation in LEO prior to injection of each outbound payload to Mars. Three payloads are the minimum required for each human mission. The baseline propulsion system for the transMars injection (TMI) stage is a Nuclear Thermal Propulsion (NTP) stage (Borowski 1993).

In the first launch of the first opportunity, in 2011, a fully fueled Earth return vehicle (ERV) is delivered to Mars orbit and aerocaptures into a 1 Sol orbit ( $250 \mathrm{~km} \times 33,700 \mathrm{~km}$ altitude) having a 24.6 hour period. The crew will use this ERV with its chemical trans-Earth injection (TEI) stage and return habitat (hab) for the trip back to earth after the completion of their surface stay and exploration.

In the second launch, in 2011, cargo delivery includes, but is not limited to: 1) an ascent vehicle to the Mars surface which includes the unfueled stage's tanks, 2) an in-situ propellant production (ISPP/ISRU) unit, 3) a nuclear surface power (NSP) unit, and 4) liquid hydrogen (to be used as a seed/reactant to produce the ascent vehicle's propellant). After this vehicle lands, the NSP unit will be autonomously deployed, approximately one kilometer from the lander, and the propellant production facility will begin producing the liquid oxygen (LOx) and liquid methane $\left(\mathrm{CH}_{4}\right)$ that will be required to launch the crew to Mars orbit for their return trip to Earth. Propellant production will be completed before the first crew's scheduled departure (TMI) from Earth.

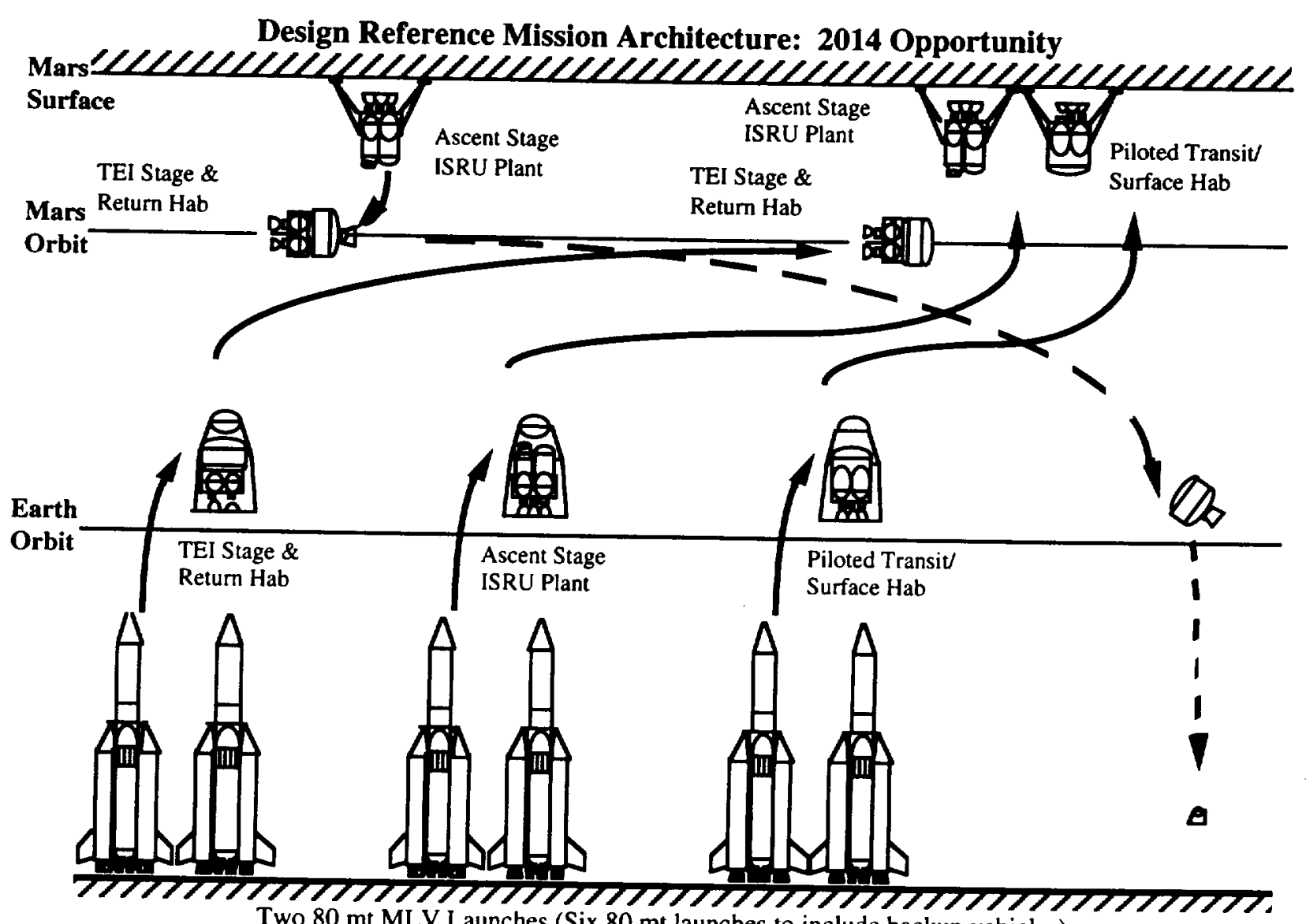

Two $80 \mathrm{mt}$ MLV Launches (Six $80 \mathrm{mt}$ launches to include backup vehicles)

FIGURE 1. Design Reference Mission Illustration. 
In the second opportunity, during January of 2014, the crew of six departs for Mars in a transivsurface hab. The outbound trip time is 161 days, with the limitation being the entry speed of $8.7 \mathrm{~km} / \mathrm{sec}$ at Mars arrival. After aerocapturing into a similar highly elliptic Mars orbit (as the 1 Sol orbit for the cargo), the crew will then do the aeroentry maneuver, descend in the transit hab to the surface propulsively, and rendezvous by means of a controlled precision landing with the previously delivered cargo elements (already on the surface).

The return leg for the first piloted visit begins with the TEI maneuver during January of 2016. The crew ascends from Mars in the Earth crew return vehicle (ECRV) and does an AR\&C-type rendezvous with the TEI stage. The return trip time is 154 days, with the entry speed of $14.2 \mathrm{~km} / \mathrm{sec}$ at Earth return. The atmospheric entry is done with the ECRV, and is the only piece of transportation hardware returned to Earth. Both portions of the piloted trajectory and the stay time on the surface are shown in Figure 2.

All transportation was sized for the current "Scrub 3.0" version of the DRM cargo (Joosten 1997). The cargo elements are the flight one return hab $(21.6 \mathrm{mt})$, the flight two surface cargo $(38.0 \mathrm{mt})$, and the piloted flight with the surface hab and additional surface cargo $(29.6 \mathrm{mt}$ ). Further definition has been received on the cargo (Connolly 1997), and should improve the packaging assessment during the next phase of the DRM development.

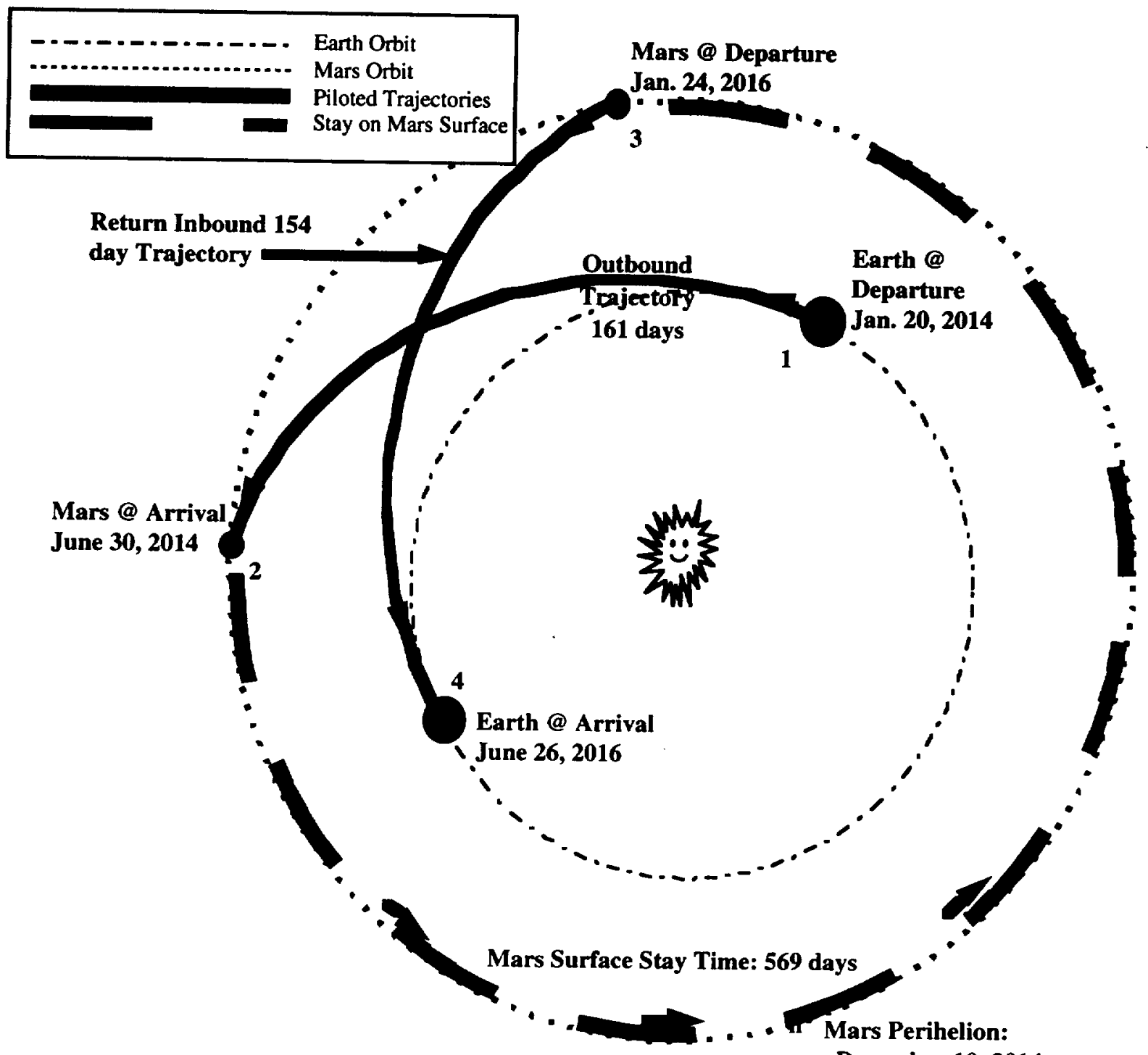

FIGURE 2. HMM DRM 2014/2016 Piloted Trajectories. 


\section{TRANSPORTATION ELEMENT DESCRIPTIONS}

The following sections describe in more detail each of the major transportation elements to the Design Reference Mission. Note that all stages are still in their conception, evolution and sizing phases.

\section{Trans-Mars Injection (TMU) Stages}

The trans-Mars injection (TMI) stage is comprised of three 66,700 newtons (N) thrust nuclear thermal propulsion (NTP) engines, giving a total thrust level of $200,000 \mathrm{~N}$ for each TMI stack. The thrust-to-weight of the engine itself is approximately 3.1. The propellant used will be liquid hydrogen $\left(\mathrm{LH}_{2}\right)$. To minimize the corresponding TMI propellant load two things are done. First, to reduce the gravity losses, the TMI maneuver is done over two separate perigee passes. This benefits the TMI delta velocity $(\Delta V)$ budget by typically $200 \mathrm{~m} / \mathrm{sec}$. Second, the boil-off rates for all the nuclear TMI stage hydrogen tanks are approximately $1.6 \%$ of the initial propellant loading per month, driving these elements of the TMI stacks to be the last pieces launched into low Earth orbit (LEO) to minimize the time spent in LEO. The longest nominal duration that a TMI stage will be in LEO in this architecture is approximately 32 days, requiring a sufficient amount of the passive thermal protection system to minimize the $\mathrm{LH}_{2}$ boil-off. The transportation elements and TMI stacks are illustrated below in Figure 3. Note that the MLV shrouds

\section{DRM “Scrub v3.0” Architecture: 2011 / 2014}

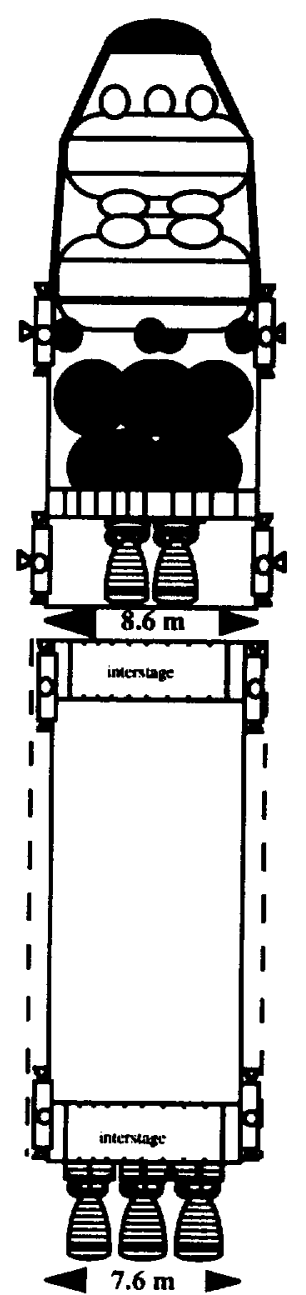

2011 TMI Stack 1: $137.3 \mathrm{mt}$
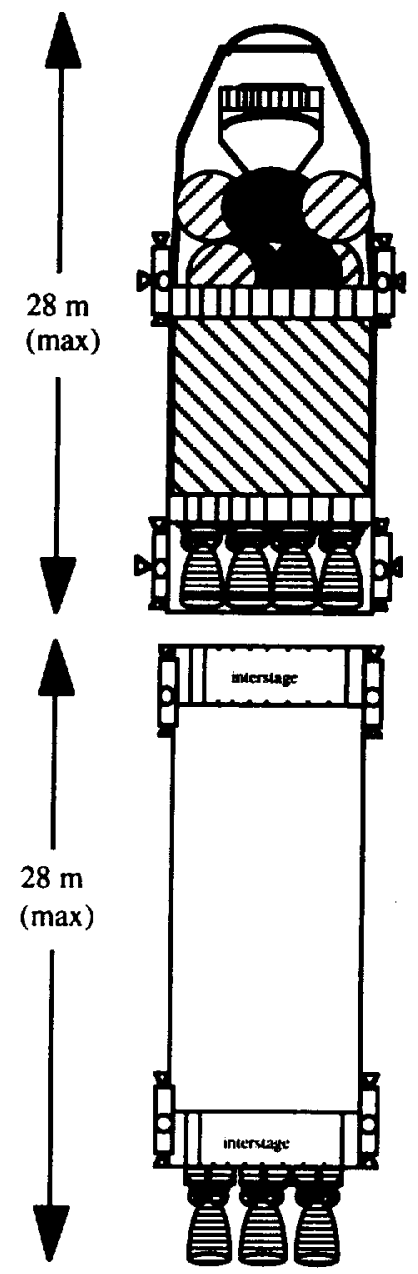

2011 TMI Stack 2: $150.8 \mathrm{mt}$
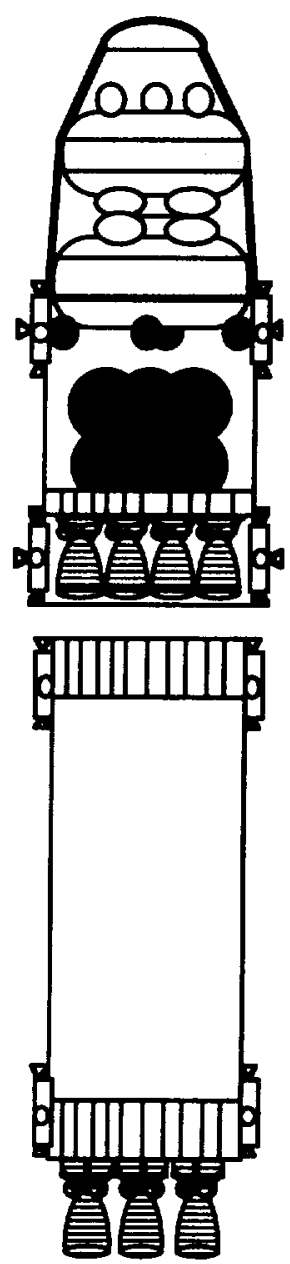

2014 TMI Stack (5): $142.4 \mathrm{mt}$

FIGURE 3. Transportation Element Illustration. 
are required to launch the TMI stages to protect the sensitive insulation required for a large $\mathrm{LH}_{2}$ tank. The diameter of these stages is reduced to $7.6 \mathrm{~m}$ to be accommodated by the inner diameter of the shroud support rings. In the last full design iteration, the TMI was baselined to be dropped immediately after TMI.

A bi-modal concept for NTP stage would provide power to the TMI stack for an extended time, and therefore the TMI stage would be carried almost all the way to Mars, being disposed of shortly before the Mars orbit capture maneuver. This has some design impact to the rest of the TMI stack, but will not be addressed in this paper.

\section{Descent/Ascent Stage}

The descent/ascent stage is a combined version of the previously separate descent and ascent stages. The impetus for this design was the minimization of the length of the payload for operations in ground facilities, minimization of the height for operations on Mars' surface, and minimizing the mass associated with the transportation (i.e. engines, tanks, etc...). The launch vehicle packaging was cut down to two MLV flights for the second TMI stack once this design was instituted. This descent/ascent stage and the surface cargo is the first element launched into LEO for the 2011 opportunity. All cargo elements are sized at $8.6 \mathrm{~m}$ outside diameter to match up with the corresponding dimension of the MLV.

The stage includes four $66,700 \mathrm{~N}$ liquid oxygen (LOx) and liquid methane $\left(\mathrm{CH}_{4}\right)$ engines. The engine chamber pressure is approximately $4.1 \mathrm{MPa}$, the mixture ratio is approximately $3.5: 1(\mathrm{O}: \mathrm{F})$, and the nozzle expansion ratio is approximately $400: 1$ for all $\mathrm{LOx} / \mathrm{CH}_{4}$ engines used in this architecture. The boil-off rates for all the non-nuclear chemical stages is approximately $0.3 \%$ of the initial propellant loading per month.

The stage is structured such that the NSP unit, $3.5 \mathrm{~m}$ on a side, can be deployed down between the nozzles canted outward at their maximum of $4^{\circ}$, and has the same clearance below the bells by the height of the landing legs. Later, after the crew reaches the surface, the four liquid hydrogen tanks can be removed through the same pathway to allow the ascent event to be performed without cargo interference. The landing $\Delta V$ budget for the stage is $1000 \mathrm{~m} / \mathrm{sec}$, with approximately $50 \%$ of the total propellant capacity of the tanks being used. However, the ascent maneuver requires all eight tanks to be fully loaded at the time of crew departure from Mars' surface, and, of course, is the driver for the tank sizing.

\section{Descent Only Stage}

The descent only stage is the stage used for the crewed landing on the surface of Mars. The stage includes also four $15,000 \mathrm{lb}_{\mathrm{f}} \mathrm{LOx} / \mathrm{CH}_{4}$ engines, and has the same landing $\Delta \mathrm{V}$ budget of $1000 \mathrm{~m} / \mathrm{sec}$. This stage requires only six of the commonly sized tanks to accommodate the piloted descent propellant loading. The previous mission used a common descent stage for both cargo and crew with a different ascent stage, for a total of two different vehicles needing to be developed and designed for this mission. The current mission design still requires only two different vehicles to be developed, although the two landers are now different. The descent only stage and the surface hab is the first element launched into LEO for the 2014 opportunity.

\section{Trans-Earth Injection (TEI) Stage}

The trans-Earth injection (TEI) stage is the stage used for the crew's return to Earth. The stage is responsible for aligning its orbit plane about Mars above the crew's landing site prior to the ascent from the surface. A plane change maneuver has been budgeted for in the stage design and sizing, and will be controlled externally from the TEI stage. This will permit a minimum of propellant needed to be made on the surface (through the ISRU processes) and help minimize performance requirements for translational $\triangle \mathrm{V}$ on both the ascent stage and the ECRV.

The stage also includes two $15,000 \mathrm{lb} / \mathrm{LOx} / \mathrm{CH}_{4}$ engines and a $\Delta \mathrm{V}$ budget of $1976 \mathrm{~m} / \mathrm{sec}$. The propellant capacity for the stage is set to be $31.4 \mathrm{mt}$ and the dry mass is approximately $4.6 \mathrm{mt}$. The TEI stage is the second element launched into low Earth orbit for the 2011 opportunity. Note that both TMI stacks will depart for Mars within a very short time of each other, to take advantage of the optimum low energy trajectories. 
An alternate version of the TEI stage, in a more nuclear architecture, also uses one of the same $66,700 \mathrm{~N}$ NTP engines as the TMI stage. The required propellant drops to $12.2 \mathrm{mt}$, but the dry mass increases to $10.0 \mathrm{mt}$. Part of this increase is the mass for the radiation shielding necessary for the crew during the TEI burn. The total size of the stage is still $14 \mathrm{mt}$ less massive, which shows some of the advantage of the much higher performance $\left(\mathrm{I}_{\mathrm{sp}}\right)$ of the nuclear propulsion technology and the current systems which employ the concept.

\section{Aerobrakes}

The aerobrake elements of the transportation are a very crucial items to the DRM architecture. First, the aerobrakes are multi-use, and second they enable part of the precision landing requirements. The Earth-to-orbit (ETO) launches with cargo utilize the aerobrake as the launch vehicle shroud. The biconic shape of the desired high lift/drag (L/D) aerobrake is very similar to that required for ascent. Granted they are heavier than a typical shroud, but they have to be lifted anyway. The aerobrakes perform the Mars orbit capture maneuver, i.e. their second use, with the current baselined limitation for the peak capture velocity of $8.7 \mathrm{~km} / \mathrm{sec}$. In the case of the surface payload and the piloted mission, a subsequent aeroentry is done with the same shell, i.e. the third use of the aerobrake. The sizing methods used for these aerobrakes dictate that a one-aeropass aerobrake should have a mass fraction of $16 \%$, while a twoaeropass aerobrake should have at least a mass fraction of $21 \%$, with a little more added in the case of the crewed entry. The aerobrakes for this architecture have masses between $10.7 \mathrm{mt}$ and $16.0 \mathrm{mt}$.

\section{Acknowledgments}

The author wishes to express his appreciation for the work of the members of the Human Mars Mission Study Team at the Marshall Space Flight Center over the last six months of FY97. The team had to work very dedicatedly in a very short term effort to assess the HMM transportation. This concept also could not be improved further without the cooperation and teamwork given by the exploration team members at the Johnson Space Center, Ames Research Center, and the Lewis Research Center also currently working on this mission concept.

\section{References}

Borowski, S. K., M. L. McGuire, E. G. Beke (1993) "Nuclear Thermal Rocket/Vehicle Design Options for Future NASA Missions to the Moon and Mars," National Aeronautics and Space Administration, TM 107071 (AIAA-934170), Lewis Research Center, Cleveland, $\mathrm{OH}$.

Weaver, D. B., M. B. Duke, B. B. Roberts (1993) "Mars Exploration Strategies: A Reference Design Mission," IAF 93-Q.1.383, NASA Johnson Space Center, Houston, TX.

Weaver, D. B., M. B. Duke (1993) "Mars Exploration Strategies: A Reference Program and Comparison of Alternative Architectures," AIAA Space Programs and Technology Conference, AIAA 93-4212, NASA Johnson Space Center, Houston, TX

Joosten, B. K., (1997) Personal Communication, NASA Johnson Space Center, Houston, TX, June 1997.

Wercinski, P. (1997) Personal Communication, NASA Ames Research Center, Moffett Field, CA, August 1997.

Connolly, J. F. (1997) Personal Communication, NASA Johnson Space Center, Houston, TX, September 1997.

Cohen, A., et al., (1989) "Report of the 90-Day Study on Human Exploration of the Moon and Mars," National Aeronautics and Space Administration Report, U.S. Government Printing Office (GPO), Washington, DC.

Stafford, T. P., et al., (1991) "America at the Threshold: Report of the Synthesis Group on America's Space Exploration Initiative," National Aeronautics and Space Administration Report, U.S. GPO, Washington, DC. 